\title{
An ex ante analysis on the use of activity meters for automated estrus detection: To invest or not to invest?
}

\author{
C. J. Rutten, ${ }^{* 1}$ W. Steeneveld,† C. Inchaisri, $\ddagger$ and H. Hogeveen ${ }^{\star} \dagger$ \\ *Department of Farm Animal Health, Faculty of Veterinary Medicine, Utrecht University, $3584 \mathrm{CL}$, Utrecht, the Netherlands \\ †Business Economics Group, Wageningen University, 6706 KN, Wageningen, the Netherlands \\ ‡Department of Veterinary Medicine, Faculty of Veterinary Science, Chulalongkorn University, 10330, Bangkok, Thailand
}

\section{ABSTRACT}

The technical performance of activity meters for automated detection of estrus in dairy farming has been studied, and such meters are already used in practice. However, information on the economic consequences of using activity meters is lacking. The current study analyzes the economic benefits of a sensor system for detection of estrus and appraises the feasibility of an investment in such a system. A stochastic dynamic simulation model was used to simulate reproductive performance of a dairy herd. The number of cow places in this herd was fixed at 130. The model started with 130 randomly drawn cows (in a Monte Carlo process) and simulated calvings and replacement of these cows in subsequent years. Default herd characteristics were a conception rate of $50 \%$, an 8-wk dry-off period, and an average milk production level of $8,310 \mathrm{~kg}$ per cow per 305 d. Model inputs were derived from real farm data and expertise. For the analysis, visual detection by the farmer ("without" situation) was compared with automated detection with activity meters ("with" situation). For visual estrus detection, an estrus detection rate of $50 \%$ and a specificity of $100 \%$ were assumed. For automated estrus detection, an estrus detection rate of $80 \%$ and a specificity of $95 \%$ were assumed. The results of the cow simulation model were used to estimate the difference between the annual net cash flows in the "with" and "without" situations (marginal financial effect) and the internal rate of return (IRR) as profitability indicators. The use of activity meters led to improved estrus detection and, therefore, to a decrease in the average calving interval and subsequent increase in annual milk production. For visual estrus detection, the average calving interval was $419 \mathrm{~d}$ and average annual milk production was $1,032,278 \mathrm{~kg}$. For activity meters, the average calving interval was $403 \mathrm{~d}$ and the average annual milk production was 1,043,398

Received January 15, 2014.

Accepted August 12, 2014.

${ }^{1}$ Corresponding author: c.j.rutten@uu.nl $\mathrm{kg}$. It was estimated that the initial investment in activity meters would cost $€ 17,728$ for a herd of 130 cows, with an additional cost of $€ 90$ per year for the replacement of malfunctioning activity meters. Changes in annual net cash flows arising from using an activity meter included extra revenues from increased milk production and number of calves sold, increased costs from more inseminations, calvings, and feed consumption, and reduced costs from fewer culled cows and less labor for estrus detection. These changes in cash flows were caused mainly by changes in the technical results of the simulated dairy herds, which arose from differences in the estrus detection rate and specificity between the "with" and "without" situations. The average marginal financial effect in the "with" and "without" situations was $€ 2,827$ for the baseline scenario, with an average IRR of $11 \%$. The IRR is a measure of the return on invested capital. Investment in activity meters was generally profitable. The most influential assumptions on the profitability of this investment were the assumed culling rules and the increase in sensitivity of estrus detection between the "without" and the "with" situation. Key words: dairy, investment analysis, sensor, estrus

\section{INTRODUCTION}

Economic losses caused by the nonoptimal reproductive performance of dairy cows have been explored in several studies (Groenendaal et al., 2004; Inchaisri et al., 2010; Giordano et al., 2012; Galvão et al., 2013). Inchaisri et al. (2010) estimated that a longer average calving interval of 407 or $507 \mathrm{~d}$, when compared with a short average calving interval of $362 \mathrm{~d}$, caused an average net economic loss of, respectively, €34 or €231 per cow per year. The longer calving intervals led to lower milk production, fewer calves, and lower costs for the management of calving. As a prolonged calving interval is associated with economic losses, optimizing reproduction management at dairy farms may be profitable.

One aspect of reproduction management is estrus detection. Studies on the efficiency of visual estrus detection have reported values around $40 \%$ (Roelofs et 
al., 2010) and 55\% (Firk et al., 2002). When optimal visual estrus detection is applied, this efficiency can be increased to a value in the range of 60 to $90 \%$ (Firk et al., 2002; Roelofs et al., 2010). However, this increase in efficiency requires an increase in labor input, varying from 1 to 3 periods of 30 min per day (Firk et al., 2002; Roelofs et al., 2010). When a farmer relies on visual estrus detection, either the detection rate is lower or the labor input tends to be higher.

The estrus detection rate could be improved without increased labor input by using sensors for automated estrus detection. The activity meter has been the most widely studied (Rutten et al., 2013) and might improve estrus detection compared with visual detection done by the farmer. Improved estrus detection increases the likelihood that a cow in estrus becomes pregnant and thereby shortens the calving interval, which is economically beneficial.

Although benefits of automated estrus detection are expected, farmers need to invest in such a system. Literature on investment in sensor technology on dairy farms is scarce. In general, the decision of a farmer to invest depends on the profitability of the investment, the farm's financial position, economic prospects, farm size, and the presence of a potential successor (Oude Lansink et al., 2001; Aramyan et al., 2007). A study among dairy farmers in Kentucky found that the actual or perceived economic benefit of using sensors influences a farmer's decision to adopt sensor technology (Russell and Bewley, 2013). Only limited knowledge is available about the economic benefit of sensor technology. Hence, a need exists for economic models to quantify the economic benefit of activity meters, so that farmers are able to make informed investment decisions.

Some studies on the economic effect of using sensor systems for automated estrus detection have been conducted. Østergaard et al. (2005) estimated the breakeven point for investing in a system for online progesterone measurements. Bewley et al. (2010b) and van Asseldonk et al. (1999a) described models for analyzing an investment in sensor systems. None of these studies considered an investment in activity meters for automated estrus detection, nor appraised any system that farmers apply in practice.

Although improved estrus detection is expected to decrease calving intervals, more factors are involved. The effect on calving interval and the subsequent effects on milk production, calves sold, and costs associated with calving are the end result of a complex system of interacting factors (e.g., the effect of milk yield on conception rate). This complex system results in uncertainty and variation in the effects of improved estrus detection, which is difficult to capture with an analytical modeling approach. Moreover, it is difficult to explore the effect of differences in the sensitivity of estrus detection using an analytical modeling approach. Therefore, a stochastic simulation study was chosen to analyze the investment in activity meters. This approach did allow for all possible reproductive events.

The aim of this study was to analyze the investment in a sensor system that uses activity meters for automated detection of estrus. For this investment analysis, a stochastic simulation model was developed, which modeled the reproductive performance of a dairy herd based on variation between individual cows. This model was parameterized with Dutch data and used to quantify the financial effects of improved estrus detection over multiple years.

\section{MATERIALS AND METHODS}

\section{Cow Simulation Model}

The cow simulation model was developed in Microsoft Excel software (Microsoft Corp., Redmond, WA). For the stochastic properties of the model, the add-in software @Risk 6 for Excel (Palisade Corporation, 2010) was used. The basic specifications of the cow simulation model were described by Inchaisri et al. (2010) and are, therefore, only described briefly here. New components of the cow simulation model are described in full detail. The new components of the model included the reproductive cycle, simulation of a series of lactations over time, the culling and replacement of cows, the estimation of feed requirements, detection performance for estrus detection, and the use of calendar weeks. An overview of all model inputs is given in Table 1, and a formal description of the implementation in @Risk of the new components in the model is given in the Appendix.

The model simulated a cow place in weekly time steps for a period of $10 \mathrm{yr}$, with 520 weekly time steps in total. Cow places were filled by cows for which all relevant fertility events were simulated (Figure 1). Multiple lactations were simulated, and at the first time step each cow started with an assigned parity. The simulation model consisted of several parallel and interlinked processes: the reproductive cycle, the lactation stage of a cow [i.e., the number of weeks in milk (WIM)], and milk production.

Reproductive Cycle. A reproductive cycle started at calving, when the cow came into milk. Then, the start of the cow's estrus cycle was simulated, which, on average, was the fourth WIM. Fertility disorders, such as metritis, were modeled as causing a delay in the onset of the cow's estrus cycle. Each estrus case had a probability to be detected. For this process, a sensitivity and specificity were defined. The specificity was needed 


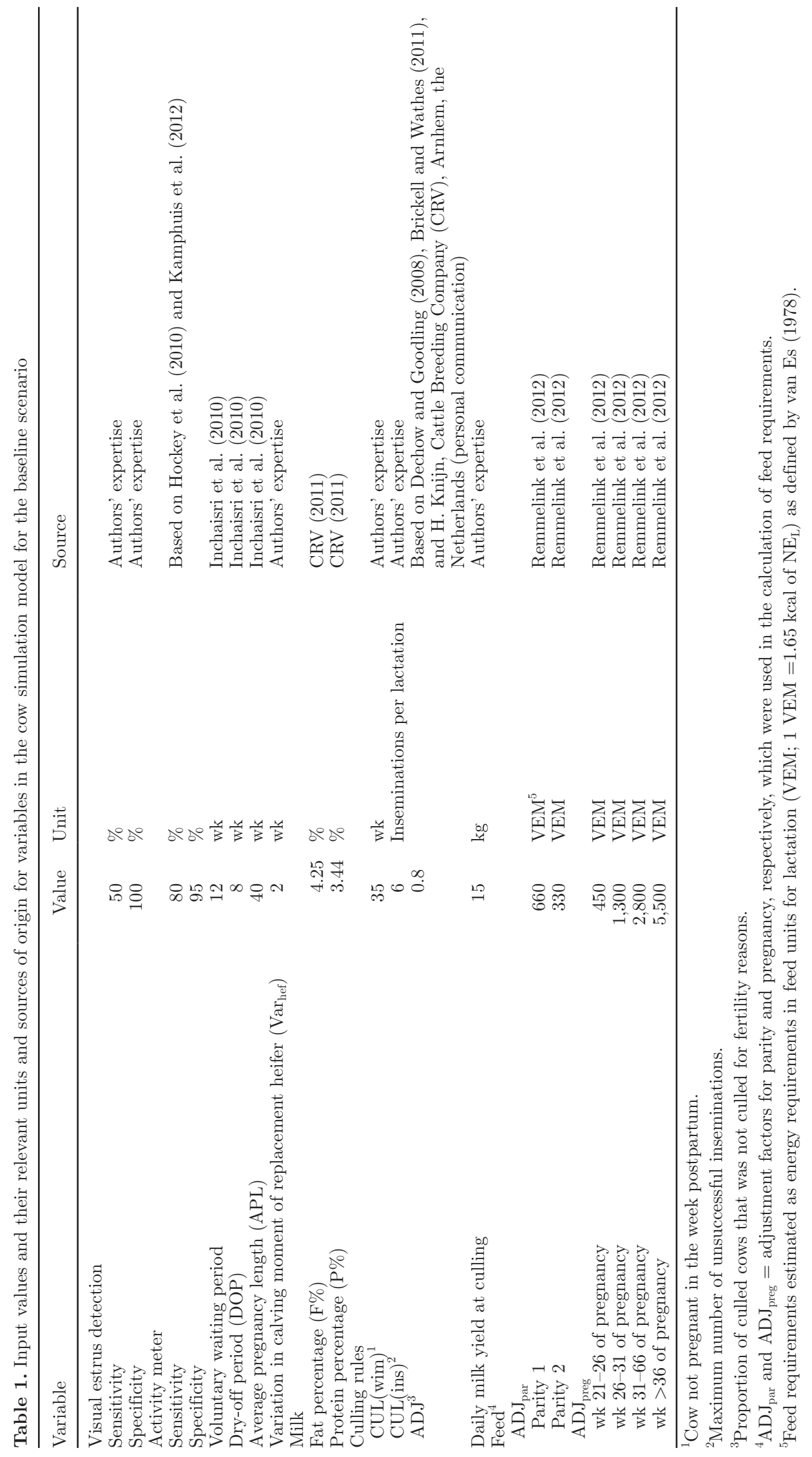




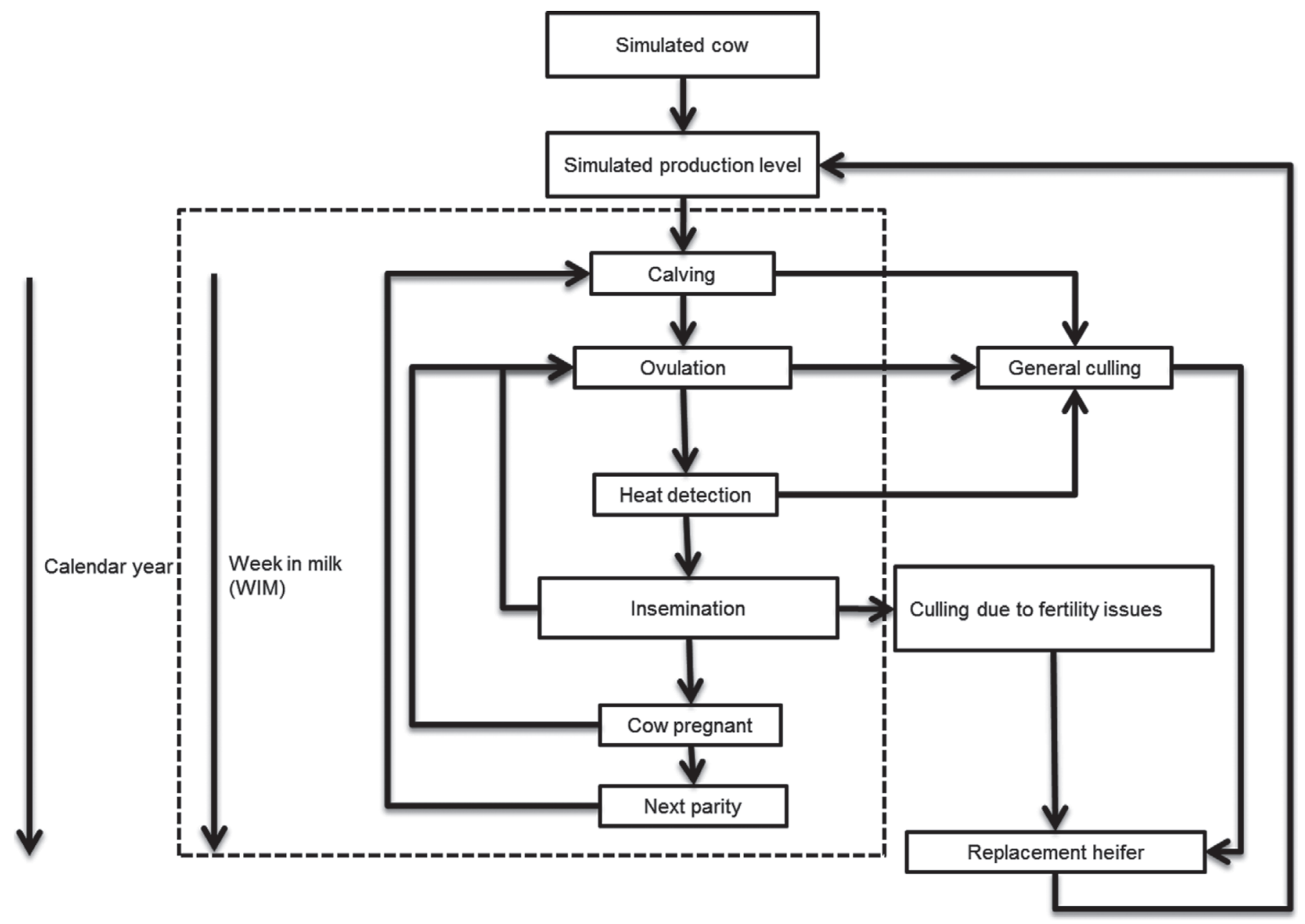

Figure 1. Schematic description of the cow simulation model, which looped through multiple lactations (shown inside the dashed frame) over simulated years. Each simulation starts in the beginning of a lactation in which several events can occur (e.g., ovulation, conception, and culling); during this lactation the cow either conceived or was culled and replaced. The lactations and fertility events were simulated over multiple calendar years.

to account for false alerts when using an automated estrus detection system (i.e., the cow was thought to be in estrus when in fact she was not). Estrus and thereby estrus detection were simulated per week; specificity resulting in false-positive alerts was simulated per day, as farmers will check for estrus alerts on a daily basis rather than a weekly basis. For visual estrus detection by the farmer, a sensitivity of $50 \%$ and a specificity of $100 \%$ (no false alerts) were assumed. For activity meters, a sensitivity of $80 \%$ and a specificity of $95 \%$ were assumed. These assumptions were based on recent intervention studies with activity meters and discussion with fertility experts (Hockey et al., 2010; Kamphuis et al., 2012; H. Knijn, Cattle Breeding Company (CRV), Arnhem, the Netherlands; personal communication). A voluntary waiting period (VWP) of 12 wk postpartum was assumed. Therefore, detected estrus events only led to insemination from wk 12 onwards. False-positive alerts were only simulated in periods when insemination could occur, as this was when false alerts led to additional costs for insemination. These periods were when a cow was both open and in a WIM that exceeded the VWP. In the simulation of insemination success, a conception rate and early embryonic death were taken into account. Simulation of estrus, estrus detection, and insemination continued until the cow was successfully inseminated or until a decision was made not to inseminate any longer. In the case of a successful insemination, the cow was eventually dried off. An average length of pregnancy of $280 \mathrm{~d}$ was assumed.

WIM. The basic process for WIM was a straightforward counting of the WIM after calving (Inchaisri et al., 2010). In the first time step of the model, a cow with a randomly assigned parity started at WIM 
$=1$. To facilitate the calculation of annual costs and revenues, this first time step was randomly assigned to a calendar week (week of the year). From that first simulated week onwards, calendar weeks were recorded. Calendar weeks were used to calculate the annual levels for milk production, feed consumption, inseminations, calves born, and culled cows. When a cow calved, the WIM was set to zero, whereas the calendar weeks counted on. Another important determinant of WIM was culling. Culling was divided into culling due to fertility problems and general culling, which included all other culling reasons. An average culling rate of 30\% (Mohd Nor et al., 2014) was assumed, and 20\% of the culled cows were assumed to be culled due to fertility problems (Dechow and Goodling, 2008; Brickell and Wathes, 2011; H. Knijn, Cattle Breeding Company (CRV), Arnhem, the Netherlands; personal communication). In the simulation model, a set of culling rules for fertility problems was defined that was representative for the Dutch farming system. A cow was culled due to fertility problems when she failed to conceive before WIM 35 or within 6 inseminations. These rules accounted for a share of $20 \%$ in the total culling rate. In contrast to culling due to fertility, general culling was modeled as a chance process. For general culling, parity-specific probabilities were used. These probabilities were derived from a frequency distribution of Dutch dairy cows, using the relative difference in the number of cows between one parity and the next. The WIM in which the cow was culled was simulated using a chance process with a higher probability early in lactation. This distribution accounted for problems arising from calving and diseases in early lactation (Seegers et al., 1998; Rajala-Schultz and Gröhn, 1999).

Milk Production and Feed Requirements. For each individual cow, a lactation curve was simulated based on farm-level milk production (input), parity, and pregnancy (Inchaisri et al., 2010). Based on the simulated lactation curve, feed requirements as energy requirements, expressed in feed units for lactation (VEM; $1 \mathrm{VEM}=1.65 \mathrm{kcal}$ of $\mathrm{NE}_{\mathrm{L}}$ ) as defined by van Es (1978), for each WIM were calculated. Higher feed requirements were simulated for first- and second-parity cows, and 4 pregnancy stages were defined to capture the different feed requirements during pregnancy (see Table 1).

\section{Simulation and Model Outputs}

A herd was assumed to consist of 130 cows in the baseline scenario. A herd size of 130 cows was chosen due to the trend of increasing herd sizes and adoption of automatic milking systems in dairy farming (de Koning, 2010). A farm of 130 cows is representative of a future
Dutch dairy farm with 2 automatic milking systems. For each herd, the model was run for 130 iterations to reflect the 130 cows in the herd. For each analysis, a total of 50,050 iterations were run, equivalent to 385 herds. Stable simulation results were achieved at 50,000 iterations, and the extra 50 iterations were needed to ensure an integer number of herds. Each iteration ran for $10 \mathrm{yr}$ for each cow place. The first $4 \mathrm{yr}$ were needed to stabilize the culling rules and the last $6 \mathrm{yr}$ were used for the investment analysis.

The cow simulation model simulated 2 situations: farms with activity meters and farms without activity meters. Farms without activity meters relied on visual estrus detection. These situations are called the "with" and "without" situations. For each situation, the model was run for 50,050 iterations. In the simulation model, the 2 situations differed only by the estrus detection rate (sensitivity) and the estrus detection specificity. For each iteration, the model outputs included total annual milk production $(\mathrm{kg} / \mathrm{yr})$, annual number of inseminations, annual number of calves, annual number of culled cows, annual number of false alerts from the activity meters, and annual feed requirements (VEM/yr).

\section{Economic Model}

To analyze the profitability of an investment in activity meters for estrus detection, the technical outputs of the cow simulation model were used as input for a capital investment analysis. The annual net cash flow on a farm was calculated as the sum of the cash flows for sold milk, feed costs, insemination costs (including false-positive alerts), calf revenues, labor costs (including visual estrus detection, viewing estrus alerts, and confirmation of estrus alerts), and annual costs of activity meters. The annual net cash flow was then averaged over all farms in the simulation for each situation, resulting in an annual net cash flow for the "with" and "without" situations. The difference in the average annual net cash flows between the "with" and "without" situations was calculated. This difference was then averaged over the last 6 simulated years. In this study, this output is called the marginal financial effect of adopting activity meters for estrus detection. It is a measure of the average marginal benefit (or loss) from using activity meters for estrus detection. The time value of money was taken into account, where appropriate, by calculating the present values of future cash flows by using a discount factor (DF). In this study, a discount rate (DR) of $5 \%$ was chosen. The calculation of the DF in year $k$ is given by Equation [1]:

$$
\mathrm{DF}_{k}=\frac{1}{(1+\mathrm{DR})^{k}} \text {. }
$$


In this study, the purchase costs of activity meters were assumed to be incurred and paid in year zero. Cash flows that arose from using the activity meter were received in subsequent years and were discounted accordingly.

Finally, the marginal financial effect of activity meters minus the investment costs was used to calculate 4 profitability indicators: the net present value (NPV), the benefit:cost (B:C) ratio, the internal rate of return (IRR), and the discounted payback period (DPBP). The NPV indicates whether the present value of the net revenues exceeds the initial outlay of the investment. The NPV is calculated as the sum of all present values of revenues and all present values of expenses. The B:C ratio gives a measure of the return on invested capital. This measure is calculated by dividing the sum of present values of benefits (returns) by the sum of present values of costs. The IRR is the discount rate at which the NPV is zero. This percentage is an indicator of the annual return on invested capital over the life time of the investment. The DPBP is the number of years needed to pay back the initial purchase costs, which is calculated using discounted cash flows. The DPBP is defined as the year in which the sum of present cash flows equals or exceeds the initial purchase costs. As the technical lifetime of the sensor system was assumed to be $10 \mathrm{yr}$, this time period was used in the calculation of all profitability measures. For each year of the technical lifetime, the marginal financial effect of activity meters was used as the annual cash flow arising from an investment in activity meters.

\section{Economic Input}

Insemination Costs. Insemination costs included the cost of sperm, the cost of the insemination service, and labor of the farmer. Based on the CRV (Arnhem, the Netherlands) pricelist (CRV, 2012), insemination costs were estimated to be $€ 30$ per insemination, assuming that, on average, 1.4 cows were inseminated per service.

Feed Costs. For the estimation of feed costs, information on VEM content was based on Dutch standard values (Remmelink et al., 2012; Vermeij, 2012). Feed costs were expressed in euros per VEM. These costs were calculated based on a standard ration in which the VEM content came from concentrates (10\%), concentrate replacing by-products (10\%), grass silage (48\%), and corn silage (32\%). For concentrates, it was assumed that standard and protein-rich concentrates were used in a 1:1 ratio. Prices averaged over the period 2005 to 2012 were used. For corn and grass silage, sale prices were used as an estimate of the opportunity costs of feeding these roughages to the farm's dairy cows instead of selling roughage (Vermeij, 2012).
Slaughter Values and Replacement Heifers. The cash flows associated with culling were the slaughter value of the culled cow (revenue) and the opportunity cost of the replacement heifer (cost). For the estimation of slaughter values, liveweights of 600,675 , and $700 \mathrm{~kg}$ were used for cows in their first, second, and third-or-higher parity, respectively (A. Sterk, Agrifirm Innovation Center, Apeldoorn, the Netherlands; personal communication). Slaughter weights were calculated assuming a dressing percentage of $60 \%$. The slaughter price, €2.01 per kilogram of slaughter weight, was an average of historical prices from the period 2003 to 2012 (LEI, 2013). It was assumed that $6.7 \%$ of all culled cows were destroyed at a cost of $€ 29$ per destroyed cow (Rendac Son BV, 2013). The opportunity costs of a replacement heifer were represented by the sale price, as the alternative for introducing a heifer into the herd is selling the heifer. For the sale price, an average of prices during the period 2003 to 2012 was used (data for 2009 were lacking; LEI, 2013). The estimated average cash flow for culling and replacing a dairy cow was calculated as the sum of the revenues from slaughter and the opportunity costs of a replacement heifer; this was $-€ 242,-€ 158$, and $-€ 130$ for a cow in first, second, and third-or-higher parity, respectively.

Labor Costs. The opportunity costs of labor were assumed to be $€ 18$ per hour (Huijps et al., 2008). For visual estrus detection, it was assumed that a farmer spent 10 min per day on estrus detection. For automated detection, it was assumed that it would take a farmer $2.5 \mathrm{~min}$ to view the alert list of the activity meters (Table 2). Two options were analyzed for dealing with the false alerts produced by activity meters. First, it was assumed that a farmer could visually confirm every alert of the activity meters; this confirmation took 5 min per alert. This assumption was implemented in the baseline scenario. Second, it was assumed that a farmer could blindly inseminate the cows after an alert, so without knowing whether the alert was a true-positive or false-positive alert. This last option was analyzed in a separate scenario.

Purchase Cost of Activity Meters. The purchase cost of activity meters was estimated based on expert information (H. Knijn, Cattle Breeding Company (CRV), Arnhem, the Netherlands; personal communication) and the expertise of the authors on commercially available sensor systems. An activity meter was assumed to cost $€ 90$ per device, and the neck collar to attach the sensor to the cow was assumed to cost $€ 18$ per collar. In addition to the sensor, a system for transmitting data and software for processing data are needed, at assumed costs of $€ 3,600$ per herd.

Annual Costs of Activity Meters. The costs of maintaining the system were assumed to be $0.5 \%$ of 


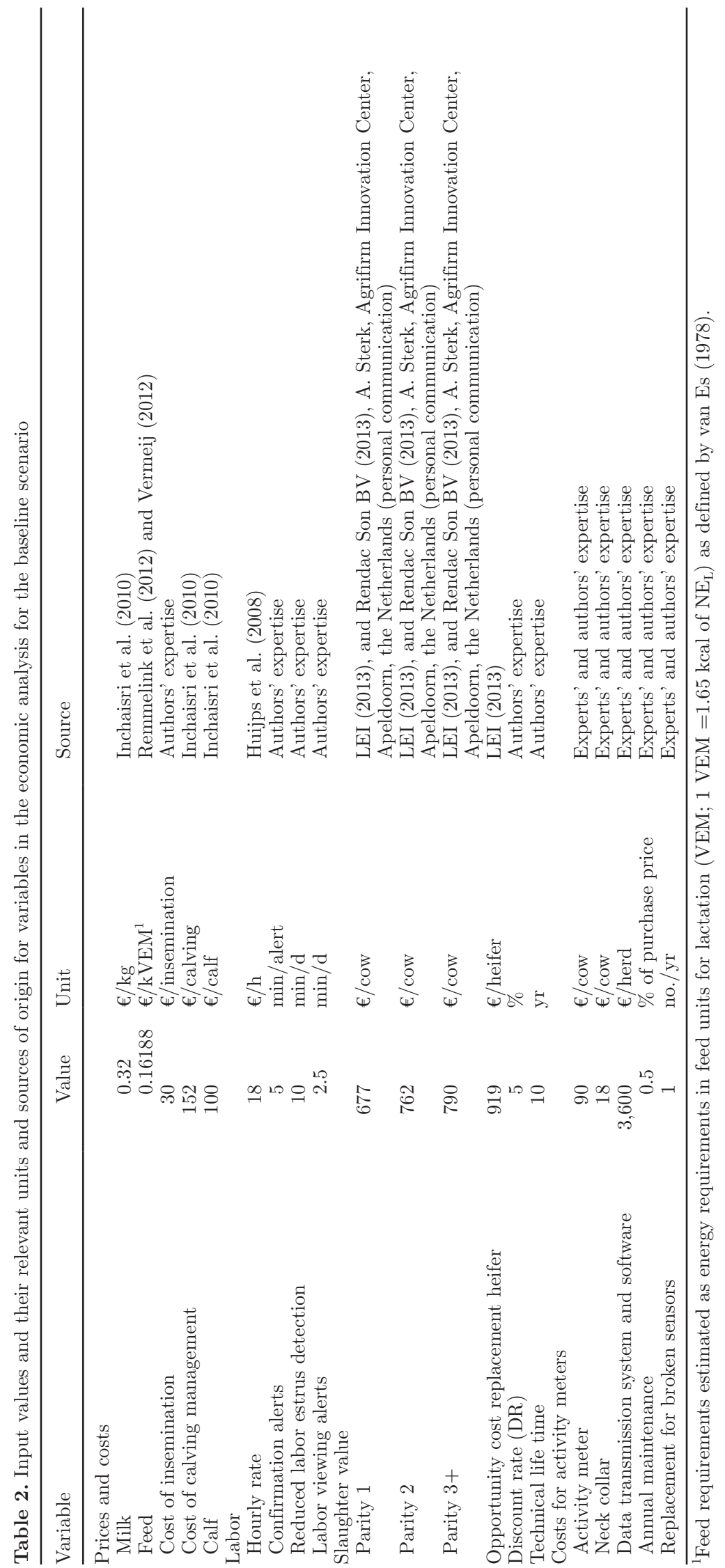


the purchase price. In addition to maintenance, it was assumed that on average 1 activity meter needed to be replaced annually (Table 2 ).

\section{Validation}

The model was validated internally, as no suitable data were available for external validation. The following steps in the validation process were undertaken: outputs were checked for plausibility, the effect of extreme input values was evaluated, and all model outputs and assumptions were critically reviewed and discussed with experts.

\section{Sensitivity Analysis}

In the baseline scenario, the situation with activity meters was compared with the "without" situation. Assumptions and input values have an effect on the results of the investment analysis. A sensitivity analysis was conducted to assess the effect of the assumptions and inputs in the following areas: culling, VWP, herd size, estrus detection, and labor costs.

Culling. Three alternative scenarios for the culling rules (culling due to fertility problems) were analyzed. In these scenarios, the share of culling due to fertility in total culling was adjusted with an adjustment factor (ADJ). The adjustment factors ensured that an average culling rate of $30 \%$ was maintained. A detailed description of the adjustment factor is provided in the Appendix. First, fully random culling was assumed (random), in which no culling rules were used and the ADJ was set to $0 \%$. Second, the culling rules were set to not pregnant in wk 40 or 6 unsuccessful inseminations (relaxed), with $\mathrm{ADJ}=10 \%$. Last, the culling rules were set to not pregnant in wk 30 or 6 unsuccessful inseminations (strict), with ADJ $=30 \%$.

$\boldsymbol{V W P}$. The baseline scenario assumed a VWP of $12 \mathrm{wk}$, resembling the current practice on Dutch dairy farms. Inchaisri et al. (2011) noted that a VWP of 9 wk is a more economically optimal choice. Therefore, a scenario with a VWP of 9 wk was also analyzed.

Herd Size. In the baseline scenario, a herd size of 130 cows was assumed. The investment was also analyzed for a herd of 65 cows or 195 cows, these herd sizes are representative of small and large Dutch dairy farms, respectively.

Estrus Detection. In practice, the visual estrus detection rate achieved by farmers may deviate between farms. It was assumed that the estrus detection rate was correlated with the time a farmer spent on estrus detection. In the sensitivity analysis, the detection rate was set at $30,40,60$, or $70 \%$, and the corresponding labor input (minutes per day) was set at $0,5,20$, or 40 , respec- tively. These values were based on the findings of Roelofs et al. (2010). In their study, labor input ranged from 60 to 120 min per day, separated in several blocks of 30 or $60 \mathrm{~min}$, whereas estrus detection rates ranged from 61 to $94 \%$. Based on those findings, levels of labor input were assumed that would not overestimate labor costs.

Similar to visual estrus detection, the estrus detection rate of activity meters may vary between farms. It was assumed that the estrus detection rate of activity meters is correlated with the specificity of estrus detection. The detection rate for the sensitivity analysis was set at $65,75,85$, or $95 \%$, and the corresponding specificity was set at $99,97.5,90$, or $85 \%$, respectively. These detection performances were based on the available literature (Hockey et al., 2010; Kamphuis et al., 2012) and accounted for the trade-off between sensitivity and specificity.

Labor Costs. Price fluctuations will influence the results of the investment analysis. Higher and lower values for the price of labor were used to account for farmers with a high $(€ 36 / \mathrm{h})$ or low $(€ 9 / \mathrm{h})$ opportunity cost of labor. Furthermore, some farmers might argue that they do not have an opportunity cost for their labor. Therefore, the investment was also analyzed without labor costs $(€ 0 / \mathrm{h})$.

\section{RESULTS}

\section{Simulation Results}

The simulation results for the baseline scenario are shown in Table 3 . The use of activity meters led to a decrease in the average calving interval per herd of 16 d, from 419 (without) to $403 \mathrm{~d}$ (with activity meters). This caused an increase in average annual milk production of approximately $11,000 \mathrm{~kg} / \mathrm{yr}$, from $1,032,278 \mathrm{~kg} /$ yr (without) to $1,043,389 \mathrm{~kg} / \mathrm{yr}$ (with). The fifth percentile results for average annual milk production were $1,032,278 \mathrm{~kg} / \mathrm{yr}$ (without) and 1,020,524 kg/yr (with activity meters). The 95 th percentile results for average annual milk production were $1,056,148 \mathrm{~kg} / \mathrm{yr}$ (without) and $1,066,806 \mathrm{~kg} / \mathrm{yr}$ (with).

In addition to the increase in milk production, the annual number of inseminations and annual number of calves born both increased with the use of activity meters, with a larger increase in inseminations than in calves born. The number of inseminations per calf was, therefore, higher for the situation with activity meters. An explanation for this increase is that a higher estrus detection rate leads to more detected estrus cases and, therefore, on average, to earlier insemination. Insemination early in lactation has a lower chance of success, especially around peak production, and therefore more inseminations are likely to be unsuccessful. 
The use of activity meters also led to a decrease in the annual number of culled cows: an average decrease of 4 culled cows per year. This decrease was a result of the culling rule that cows were culled if they were not pregnant by wk 35 of lactation. When the estrus detection rate increased, cows became pregnant earlier (hence the shorter calving interval), and fewer cows were culled for not becoming pregnant by wk 35 .

\section{Financial Results}

The effects of the technical simulation results on the annual financial results are shown in Table 3. The increased milk production due to the use of activity meters had the largest effect on the financial results. The increased milk production led to an increase in the annual revenue of $€ 3,558$ per year. The reduced number of culled cows and reduced labor input decreased the annual costs by $€ 942$ and $€ 261$, respectively. In the situation with activity meters, higher feed consumption increased costs by €1,035 per year. The larger numbers of inseminations and calves born also increased the annual costs, by $€ 667$ and $€ 143$ per year, respectively. Overall, the difference in average annual net cash flow between the "with" and "without" situations, termed the marginal financial effect, was $€ 2,827$. At the fifth percentile, the marginal financial effect was $€ 2,968$. This was representative of low-cash-flow farms. At the 95th percentile, the marginal financial effect was $€ 2,633$, representative of high-cash-flow farms. The marginal financial effect for low- and high-cash-flow farms was used further in the investment analysis.

\section{Investment Analysis}

The results for the investment analysis are presented in Table 4, for the different options for dealing with false estrus alerts from the activity meter. For farms that first visually confirmed estrus alerts, the average NPV of investing in activity meters was $€ 4,098$, with an NPV of $€ 587$ for low-cash-flow farms and $€ 2,604$ for high-cash-flow farms. The average B:C ratio was 1.23, with a ratio of 1.33 for low-cash-flow farms and 1.15 for high-cash-flow farms. As the NPV was positive and the $\mathrm{B}: \mathrm{C}$ ratio greater than 1 , the investment was profitable. On average, the return on invested capital (the IRR) was $10 \%$, with $11 \%$ for low-cash-flow farms and $8 \%$ for high-cash-flow farms. The investment was paid back in $8 \mathrm{yr}$ for an average farm, with 8 yr for low-cash-flow farms and $9 \mathrm{yr}$ for high-cash-flow farms. When a farmer inseminated blindly upon every alert, the investment was not profitable. 
Table 4. Investment results for investing in activity meters on a dairy farm with 130 cows for the different options for dealing with false-positive estrus alerts: the blind and confirmation scenarios

\begin{tabular}{lcc}
\hline & \multicolumn{2}{c}{ Mean (low cash flow/high cash flow) } \\
\cline { 2 - 3 } Item & Blind $^{2}$ & Confirmation $^{3}$ \\
\hline Cash flow $(€ /$ yr $)$ & $-324(-35 /-532)$ & $2,287(2,968 / 2,633)$ \\
Purchase $(€ /$ herd $)$ & $17,728(-)$ & $17,728(-)$ \\
NPV $^{4}(€ /$ herd $)$ & $-21,618(-19,389 /-23,229)$ & $4,098(5,887 / 2,604)$ \\
$\mathrm{B}^{5}$ & $-0.22(-0.09 /-0.31)$ & $1.23(1.33 / 1.15)$ \\
$\operatorname{IRR}^{6}(\%)$ & $\mathrm{NA}^{7}(\mathrm{NA} / \mathrm{NA})$ & $10(11 / 8)$ \\
$\operatorname{DPBP}^{8}(\mathrm{yr})$ & $\mathrm{NA}(\mathrm{NA} / \mathrm{NA})$ & $8(8 / 98)$ \\
\hline
\end{tabular}

${ }^{1}$ Mean values are presented with results for low and high cash flow farms in parentheses; these indicators were calculated using the 5th and 95th percentile results for the marginal financial effect of activity meters (difference in annual net cash flow between the "with" and "without" situations).

${ }^{2}$ Blind refers to insemination after an alert without visual confirmation.

${ }^{3}$ Confirmation refers to visual confirmation of all alerts before insemination.

${ }^{4}$ Net present value (the sum of all present revenues and present expenses).

${ }^{5}$ Benefit:cost ratio [the ratio between the sum of present benefits (returns) and the sum of present costs].

${ }^{6}$ Internal rate of return (the discount rate at which the NPV is zero).

${ }^{7} \mathrm{NA}=$ not applicable (cash flow was negative, so no numerical solution for the IRR was possible).

${ }^{8}$ Discounted payback period, the number of years needed to payback the initial purchase costs using discounted cash flows.

\section{Sensitivity Analysis}

Culling. Different culling rules for fertility problems caused changes in the number of cows culled, annual culling costs, and annual milk production. The IRR for the 3 different scenarios are shown in Table 5. These were $18 \%$ (random), $18 \%$ (relaxed), and $-12 \%$ (strict). For these scenarios, the share of cows culled for fertility problems in the total number of cows culled differed. The effect of this share on the marginal financial effect and IRR is shown in Figure 2.

$\boldsymbol{V W P}$. When the VWP was shortened from 12 to 9 wk, average calving intervals were shorter (data not shown) for both the "without" situation (403 d) and the situation with activity meters $(385 \mathrm{~d})$. However, with a VWP of $9 \mathrm{wk}$, the IRR for investing in a sensor system was $10 \%$ (see Table 5), which was similar to the IRR in the baseline scenario. The marginal financial effect was $€ 2,844$ for a VWP of 9 wk (Table 5), which was slightly higher than in the baseline scenario.

Herd Size. For a herd of 65 cows, the marginal financial effect was $€ 1,779$, which was much lower than that for a herd of 130 cows (see Table 5). However, this smaller herd had a slightly higher IRR (11\%). For a herd of 195 cows, the marginal financial effect was $€ 3,870$, which was higher than that for a herd of 130 cows. The IRR for this larger herd (9\%) was slightly lower than the baseline scenario.

Estrus Detection. When sensitivity increased, the average calving interval shortened and the average annual milk production increased accordingly (data not shown). An increase in sensitivity had a stronger effect on the average calving interval at low sensitivities than at high sensitivities. For instance, increasing the sensitivity from 30 to $40 \%$ shortened the average calving interval by $7 \mathrm{~d}$, from 435 to $426 \mathrm{~d}$, whereas increasing the sensitivity from 85 to $95 \%$ shortened the average calving interval by only $2 \mathrm{~d}$, from 401 to $399 \mathrm{~d}$.

In Figure 3 the marginal financial effect and IRR are shown for a fixed sensitivity of $80 \%$ with varying specificities, and for a fixed specificity of $95 \%$ with varying sensitivities. For a sensitivity of $70 \%$ with specificity fixed at $95 \%$, the IRR was below the discount rate of $5 \%$, indicating that the investment was not profitable. Linear trend lines are included in Figure 3 to show the relationships between detection performance, and cash flow and IRR. An increase in sensitivity had a larger effect on cash flow and IRR than an increase in specificity had.

When the sensitivity of visual estrus detection changed, which was modeled by changing the labor input for visual estrus detection, the investment in activity meters was more profitable than in the baseline scenario (Table 5). Although the investment was more profitable for all scenarios, labor inputs smaller than the baseline level had a different effect than larger labor inputs. In the scenarios with a low labor input and low sensitivity for visual estrus detection, the use of activity meters meant a large improvement in estrus detection and, therefore, in the technical results. On the other hand, in the scenarios with a high labor input and high sensitivity for visual estrus detection, the improvement in estrus detection was relatively smaller, but the use of the activity meter led to a larger saving in labor input.

When the sensitivity and specificity of activity meters was changed, the IRR was not always positive. 


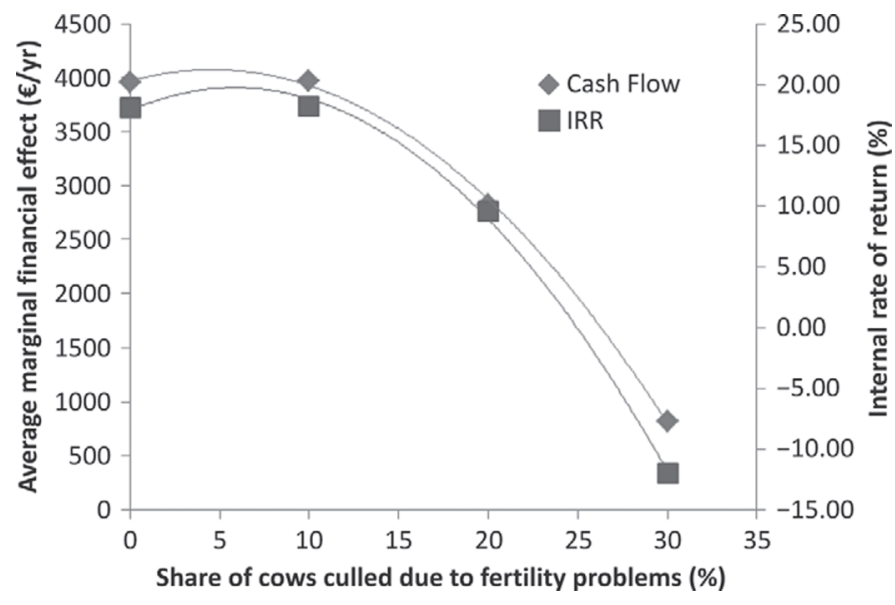

Figure 2. Effect of the share of cows culled for fertility problems on the average marginal financial effect (difference in annual net cash flow between the "with" and "without" situations) and internal rate of return (IRR) for investing in activity meters on a dairy farm with 130 cows. The $\mathrm{x}$-axis represents the share (\%) of cows culled for fertility problems in the total number of culled cows. Polynomial trend lines are included in the graph.
In the scenarios with a high estrus detection rate for the activity meter ( 85 and $95 \%$ ), the IRR was higher than in the baseline scenario (Table 5), whereas in the scenarios with a low sensitivity (65 and $75 \%$ ), the IRR was lower than in the baseline scenario. Moreover, the IRR was negative for the scenario with a sensitivity of $65 \%$. Therefore, the corresponding NPV would not have exceeded zero. In addition to the sensitivity, the specificity of the activity meters was changed. A high specificity was combined with a low sensitivity and vice versa. The lower specificity resulted in higher labor costs than for the scenarios with high specificities. On the other hand, in the scenarios with low sensitivity, these labor costs were lower. Moreover, in all of the scenarios, the investment was more profitable when a farmer confirmed estrus alerts before insemination (Table 6).

Labor Costs. Changing the opportunity costs of labor influenced both the marginal financial effect and IRR (Table 5). If the opportunity costs of labor were

Table 5. Marginal financial effect (difference in annual net cash flow between the "with" and "without" situations) and internal rate of return (IRR) for different scenarios in the sensitivity analysis

\begin{tabular}{|c|c|c|}
\hline \multirow[b]{2}{*}{ Scenario } & \multicolumn{2}{|c|}{ Mean (low cash flow/high cash flow) ${ }^{1}$} \\
\hline & Marginal financial effect $(€ / y r)$ & $\operatorname{IRR}(\%)$ \\
\hline Baseline $^{2}$ & $2,827(2,968 / 2,633)$ & $10(11 / 8)$ \\
\hline Random $^{3}$ & $3.953(4,547 / 3,473)$ & $18(22 / 15)$ \\
\hline Relaxed $^{4}$ & $3,972(4,459 / 3,657)$ & $18(22 / 16)$ \\
\hline Strict $^{5}$ & $819(949 / 472)$ & $-12(-10 /-19)$ \\
\hline VWP $9^{6}$ & $2,844(2,929 / 2,748)$ & $10(10 / 9)$ \\
\hline Herd of 65 cows & $1,779(1,936 / 1,655)$ & $11(13 / 9)$ \\
\hline Herd of 195 cows & $3,870(4,034 / 3,063)$ & $9(10 / 4)$ \\
\hline \multicolumn{3}{|l|}{ Activity meters (with) ${ }^{7}$} \\
\hline sn 65 and sp 99 & $1,620(1,529 / 1,587)$ & $-2(-3 /-2)$ \\
\hline sn 75 and sp 97.5 & $2,428(2,420 / 2,251)$ & $6(6 / 8)$ \\
\hline sn 85 and sp 90 & $3,030(3,181 / 3,127)$ & $11(12 / 12)$ \\
\hline sn 95 and sp 85 & $3,321(3,404 / 2,913)$ & $13(14 / 10)$ \\
\hline \multicolumn{3}{|l|}{ Visual (without) ${ }^{8}$} \\
\hline sn 30 and labor 0 & $3,591(4,057 / 3,291)$ & $15(19 / 13)$ \\
\hline sn 40 and labor 5 & $3,102(3,355 / 2,893)$ & $12(14 / 10)$ \\
\hline sn 60 and labor 20 & $2,921(3,038 / 2,814)$ & $10(11 / 9)$ \\
\hline sn 70 and labor 40 & $4,417(4,487 / 4,382)$ & $21(22 / 20)$ \\
\hline \multicolumn{3}{|l|}{ Labor costs } \\
\hline No labor costs $(€ 0 / \mathrm{h})$ & $2,631(2,735 / 2,491)$ & $9(8 / 10)$ \\
\hline Low labor costs $(€ 9 / \mathrm{h})$ & $2,729(2,858 / 2,547)$ & $9(10 / 7)$ \\
\hline High labor costs $(€ 36 / \mathrm{h})$ & $3,022(3,196 / 3,806)$ & $11(12 / 9)$ \\
\hline
\end{tabular}

${ }^{1}$ Mean results are presented with results for low and high cash flow farms in parentheses, these indicators were calculated using the 5th and 95th percentile results for the marginal financial effect of activity meters (difference in annual net cash flow between the "with" and "without" situations).

${ }^{2}$ The baseline scenario assumed the following: a sensitivity of $80 \%$ with a specificity of $95 \%$ in the "with" situation, a sensitivity of $50 \%$ with a specificity of $100 \%$ in the "without" situation, a voluntary waiting period (VWP) of $12 \mathrm{wk}, 20 \%$ of the culling is due to fertility problems, and labor costs of $€ 18 / \mathrm{h}$.

${ }^{3}$ Zero percent of culled cows were culled for fertility problems.

${ }^{4}$ Ten percent of culled cows were culled for fertility problems.

${ }^{5}$ Thirty percent of culled cows were culled for fertility problems.

${ }^{6}$ Voluntary waiting period (VWP) of $9 \mathrm{wk}$.

${ }^{7}$ Scenarios varied in the sensitivity (sn; \%) and specificity (sp; \%) of estrus detection.

${ }^{8}$ Scenarios varied in the sn (\%) and labor input (min) for estrus detection. 
either zero or low ( $€ 9 / \mathrm{h})$, the marginal financial effect and IRR were lower than in the baseline scenario. When high opportunity costs of labor $(€ 36 / \mathrm{h})$ were assumed, the marginal financial effect and IRR were higher than those of the baseline scenario. However, the magnitudes of the effects were relatively small for all labor scenarios; the scenarios differed from the baseline scenario by about $€ 200$ per year for the marginal financial effect and $1 \%$ for the IRR.

\section{DISCUSSION}

A stochastic simulation model was used, which simulated the reproductive performance of a herd of dairy cows over time. This model was used to analyze the investment in a sensor system with activity meters for the automated detection of estrus. The average IRR of the investment in activity meters was $11 \%$ and the most influential inputs in the model were the assumed share of culling for fertility reasons and the increase in sensitivity of estrus detection between the "without" and the "with" situation. When a farmer followed strict culling rules and would stop inseminating cows that had not conceived by WIM $=30$, then the average return on investment was negative. The IRR was also negative when the sensitivity in the "with" situation was $65 \%$ or when a farmer would blindly inseminate his cows upon an estrus alert. In all other scenarios, the average return on investment was positive. As the cow simulation model was based on the previous work of Inchaisri et al. (2010), the technical results in the current study are similar to those of that study.

The average calving interval was $419 \mathrm{~d}$ for a scenario with baseline culling rules and $427 \mathrm{~d}$ (data not shown) for a scenario with random culling rules (i.e., no culling rules for fertility problems). Both of these scenarios assumed a sensitivity of visual estrus detec-

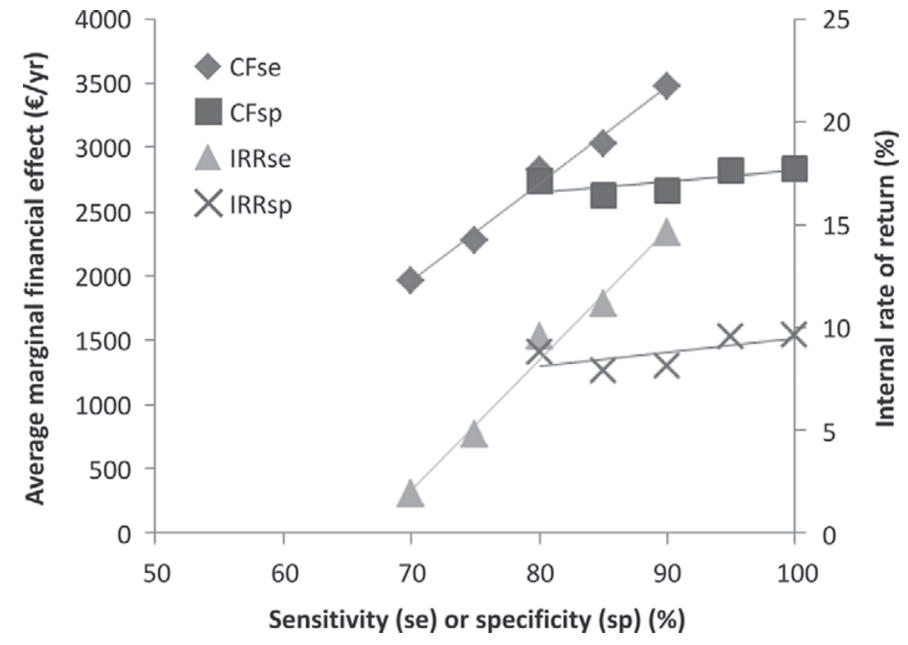

Figure 3. Effect of sensitivity (se) and specificity (sp) of estrus detection on the average marginal financial effect [difference in annual net cash flow (CF) between the "with" and "without" situations] and internal rate of return (IRR) of investing in activity meters on a dairy farm with 130 cows. The $\mathrm{x}$-axis represents different se and $\mathrm{sp}$ in percent for estrus detection by activity meters. For different se, the corresponding sp was fixed at a baseline level of $100 \%$ in the "without" situation. For different specificities, the corresponding sensitivity was fixed at a baseline level of $80 \%$.

tion of $50 \%$. These intervals are in line with the average calving interval in the Netherlands of $422 \mathrm{~d}$ (CRV, 2011). The lowest and highest average calving intervals in this study were 385 and $435 \mathrm{~d}$ (data not shown). The lowest interval was observed for the scenario with a VWP of $9 \mathrm{wk}$, and the highest interval for visual estrus detection with a sensitivity of $30 \%$. These intervals also seem realistic when compared with the 25 th and 75 th percentiles of calving intervals for Dutch dairy farms: 391 and $465 \mathrm{~d}$, respectively (CRV, 2011). In the current study, the average calving intervals did not resemble extremely long or short calving intervals. This is as expected, as no extreme values were assumed for disease

Table 6. Marginal financial effect (difference in annual net cash flow between the "with" and "without" situations) and internal rate of return (IRR) of investing in activity meters for different levels of sensitivity (sn; \%) and specificity (sp; \%) of estrus detection, and for different options for dealing with false-positive estrus alerts

Average (low cash flow/high cash flow) ${ }^{1}$

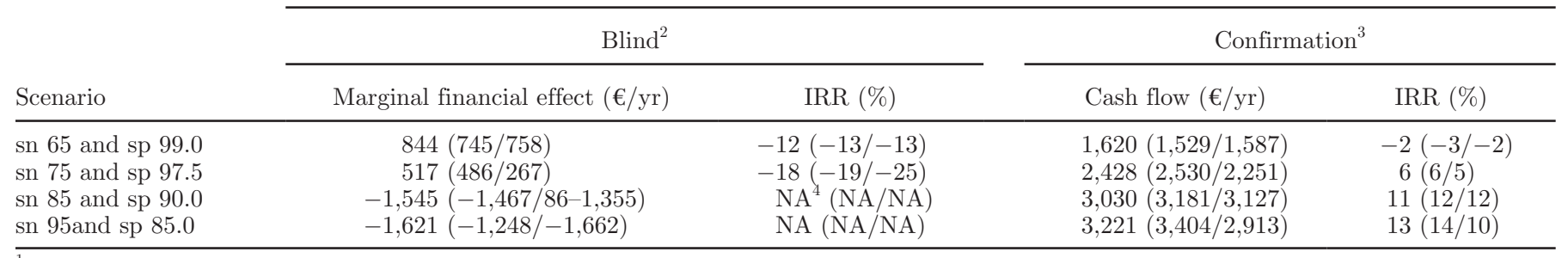

${ }^{1}$ Averages are presented with results for low- and high-cash-flow farms in parentheses, calculated using the 5th and 95th percentile results for the marginal financial effect of activity meters.

${ }^{2}$ Blind refers to insemination after an alert without visual confirmation.

${ }^{3}$ Confirmation refers to visual confirmation of all alerts before insemination.

${ }^{4} \mathrm{NA}=$ not applicable (cash flow was negative, so no numerical solution for the IRR was possible). 
incidence, ovulation rate, conception rate, VWP, and culling rules.

In the current study, farms using visual estrus detection had an average calving interval of $419 \mathrm{~d}$ and an average annual milk production of approximately 7,938 $\mathrm{kg} /$ cow. For farms with activity meters, the average calving interval was $403 \mathrm{~d}$ and the average annual milk production was approximately $8,030 \mathrm{~kg} /$ cow. These technical results can be compared with other studies. Inchaisri et al. (2010) reported a calving interval of 407 $\mathrm{d}$ and annual milk production of $7,775 \mathrm{~kg} /$ cow for a visual estrus detection rate of $50 \%$, and $362 \mathrm{~d}$ and 8,068 $\mathrm{kg} / \mathrm{cow}$ for a detection rate of $70 \%$. As these models differed in some areas, results were not identical. One main difference is that at an estrus detection rate of $70 \%$, the VWP and fertility inputs were also changed in the study of Inchaisri et al. (2010). Another study, which analyzed different breeding strategies, reported calving intervals varying from 14.1 to 14.9 mo (Giordano et al., 2011), which corresponds to approximately 420 d. Last, another simulation study reported an average of 120 to $131 \mathrm{~d}$ open (Giordano et al., 2012), which would result in calving intervals in the range of 400 to $411 \mathrm{~d}$. The results of the current study are in line with these findings.

Only a few publications on the economics of sensor systems are currently available. The economic benefits of automated BCS (Bewley et al., 2010a), the breakeven point of online progesterone measurements (Østergaard et al., 2005), and the potential economic benefits of information technology (van Asseldonk et al., 1999b) have been analyzed. The results of those studies are not comparable with the current study, as the focus was on different sensors. van Asseldonk et al. (1999b) quantified the potential benefits of automated estrus detection. The positive financial effect of automated estrus detection was confirmed in our study. However, large differences exist between the 2 studies, mainly in the methodology, assumptions, and estrus-detection systems.

In the simulation of culling and replacement, the framework of the current model had some limitations. An important limitation was the exclusion of herd dynamics, as only one cow place was modeled in each iteration. In reality, a cow that is to be culled for fertility reasons will stay in the herd until she is ready for slaughter or is pushed out of the herd when a heifer calves. The unexpected culling of a cow (e.g., the cow dies at parturition) could cause an empty spot in the herd, if no heifer calves at the moment that the cow was culled. The effect of these dynamics on our analysis is difficult to determine. The effect would depend strongly on the WIM in which a heifer would push a cow out of the herd, and on the difference in milk production between a cow in late lactation and a heifer in early lactation. Another limitation was the estimation of slaughter values. We used average slaughter values, which did not take lactation stage into account. Although this methodology simplifies reality, no major biases are expected, as the analysis used differences between average values at the herd level.

One of the most influential assumptions in the cow simulation model was the method used to simulate culling of dairy cows. One method was random culling (used for general culling), where an individual cow was randomly selected for culling using a probability per lactation. The advantage of this random method is that the distribution of cows over various parities remained relatively constant. However, as increased estrus-detection rates cause shorter calving intervals, the random culling process will lead to an increase in the annual number of culled cows for the situation with the activity meter. Culling is often not a random process, and fertility problems in general, and more specifically failure to conceive, are known reasons for culling (Dechow and Goodling, 2008; Brickell and Wathes, 2011; Demeter et al., 2011). Some studies have suggested that approximately $20 \%$ of the cows were culled because of fertility problems (Dechow and Goodling, 2008; Brickell and Wathes, 2011). With the improvement in estrus detection from using the activity meter, a decrease in the number of cows culled for fertility problems was expected. This positive effect on culling was simulated using culling rules for fertility problems. However, these rules did not capture the complexity inherent in optimizing culling decisions for individual cows in practice (Demeter et al., 2011). However, the culling rules in the current study attempted to approximate, given the structure of the model, the approach farmers use in practice rather than the economically optimal option. These culling rules may, therefore, provide more realistic results than the assumption of optimal culling decisions used in other models (e.g., Demeter et al., 2011) because, in practice, culling decisions are not always economically optimal.

The results of the sensitivity analysis show that the lowest positive return on investment for activity meters was found at a sensitivity of $70 \%$ (IRR $=3.5 \%$; see Figure 3). Whether the investment is profitable in this scenario depends on the minimal return on investment that a dairy farmer requires. For Dutch circumstances, a DR of $5 \%$ might be appropriate as a minimal return on investment. Minimal returns on investment in the Netherlands may be relatively low due to low inflation rates (an average of $2.32 \%$ between 1990 and 2012, ranging from 1.1 to $4.5 \%$; Statistics Netherlands, 2013) and the attitude of Dutch dairy farmers, who, in general, tend to consider the risks involved in dairy farming to 
be low and not require high returns. Some Dutch dairy farmers might even consider a DR of $5 \%$ to be high. However, farmers in other regions may consider the risks involved in dairy farming to be higher and, thus, require higher returns. The IRR was considered to be a more flexible estimate of the return on investment than other investment measures, such as the NPV, especially when extrapolating the results of the current study to other countries and circumstances.

In scenarios with high visual estrus detection rates, higher labor inputs were assumed and this resulted in greater labor savings for the situation with automated estrus detection. The labor inputs used in the current study were based on Roelofs et al. (2010). They reported a sensitivity for visual estrus detection of 94 or $76 \%$, when observations were done twice per day at dusk and quiet times for 60 or 30 min, respectively. However, detection rates were lower by 35 to $46 \%$ when observations took place twice per day for $30 \mathrm{~min}$ at milking times. This observation indicates that combining estrus detection with other activities might be less effective than observing the cows while no other work is done. From an economic perspective, spending more time on estrus detection is likely to be less profitable than investing in activity meters.

An increase in sensitivity led to higher milk production and fewer cows culled for failing to conceive. A decrease in specificity caused more false alerts, which meant higher labor and insemination costs. The changes in milk production and cows culled had a larger effect on the marginal financial effect than the higher labor input for confirmation. Therefore, an increase in sensitivity had a greater effect on the marginal financial effect and IRR than a similar decrease in specificity. However, farmers perceive false-positive alerts as a more important problem (Mollenhorst et al., 2012). Four explanations for this contradiction are possible. First, the survey of Mollenhorst et al. (2012) considered mastitis, which is a different condition from estrus and, therefore, the importance of false alerts could differ. Second, the opportunity cost of a farmer's labor could have been underestimated in the current study. Third, the problem with a false alert may not be the actual time input, but rather the annoyance of checking a cow when nothing is going on. This annoyance could decrease the level of trust in an automated detection system, which would influence the perceived value of the system for a farmer. Fourth, a farmer might want to trust the detection system blindly, which is not profitable with the estimated numbers of false alerts in the current study.

Blind insemination was not profitable in this study, because the extra costs for insemination after a false alert did exceed the benefits arising from the use of the activity meter and labor savings. Confirmation of alerts was almost always profitable, as the labor costs for confirming alerts were lower than the extra insemination costs for blind insemination. With a higher specificity this effect became stronger; however, the associated lower sensitivity meant that the investment in activity meters was not profitable in these scenarios.

The influence of labor costs on the profitability of an investment in activity meters was small. This small effect was due to small labor input for visual estrus detection that was assumed in the baseline scenario. This was assumed because most farmers spend time on visual estrus detection while doing other tasks in the barn. Therefore, most of the labor input was considered to be a sunken cost. Varying results have been reported for the relationship between labor input and sensitivity of visual estrus detection (Roelofs et al., 2010). Detection methods using strict scoring systems and time blocks do not represent the current Dutch practice. Therefore, it is difficult to measure how much labor dairy farmers would save in practice by using automated estrus detection. Furthermore, studies on labor and sensitivity of visual estrus detection (Firk et al., 2002; Roelofs et al., 2010) appear unable to account for the herdsmanship of the farmer. Variation between farms in the sensitivity of visual estrus detection with the same labor input is, therefore, likely. Another important factor is herd size. Compared with a herd of 130 cows, a farmer with a herd of 65 cows is likely to achieve a higher sensitivity of visual estrus detection with a lower labor input.

In practice, variation in detection performance will occur for both visual estrus detection and activity meters. For visual estrus detection, this variation will be related to the herdsmanship of the farmer, herd size, and workload of the farmer. For activity meters, this variation will depend on the detection algorithm, which may work better on one farm than on another. This effect could be caused by differences in farm structure (barn type and grazing), cow health, and cow behavior. Another potential reason is that the performance reported in studies that use a strict protocol and structured experimental setup is not comparable with daily practice on a dairy farm.

Sensor systems for automated estrus detection based on cow behavior include activity meters, pedometers, and 3-dimensional (3D) accelerometers. Studies on the performance of these systems reported comparable sensitivities and specificities for estrus detection, although gold standards varied (Rutten et al., 2013). Because the gold standards differed, it cannot be concluded that performances are equal for these 3 sensor systems. The current study focused on activity meters because their performance was validated with progesterone as a gold standard. For the current study, studies that used 
progesterone as a gold standard (Hockey et al., 2010; Kamphuis et al., 2012) were considered to be the most reliable for evaluating the performance of automated estrus detection based on cow behavior. However, in practice, it is possible that the performance of activity meters, pedometers, and 3D accelerometers is comparable. No evident reason exists for one type of sensor to perform better than the others in measuring cow behavior. However, the algorithm used in the sensor system will be important. The results of this study may provide some insight into the profitability of an investment in pedometers and the $3 \mathrm{D}$ accelerometer.

In this study, nonreproductive diseases were excluded, although diseases such as lameness and metabolic problems do influence fertility. Inclusion of these effects could result in more realistic simulations; however, it would be difficult to quantify the effects to make them useable for simulation. It would be especially relevant to include lameness because this disease influences cow walking behavior and hence activity (Bruijnis et al., 2010). Activity meters could be used to detect lameness in addition to estrus, which is likely to increase the revenues from the sensor system (Rutten et al., 2013).

The current study used a simulation model, which made it easy to explore the effects of changing a single variable, such as estrus detection rate. However, these simulation results can differ from results in practice. It would be interesting to compare our results with profitability indicators calculated with real farm data. The advantage this comparison is that differences between farms can then be studied. Although the model was parameterized using Dutch data, the results are also applicable to dairy farming in other countries. Generally, the effect of automated estrus detection will be comparable, and investment is also likely to be profitable. However, differences in factors such as production and price levels will change the technical and financial outcomes of the calculations.

\section{CONCLUSIONS}

This study analyzed an investment in activity meters for automated estrus detection on an average dairy farm, using a simulation model parameterized with Dutch data. With an average IRR of 11\%, investing in activity meters for estrus detection was profitable. Other indicators such as NPV, B:C ratio, and DPBP confirmed this conclusion. The increase in sensitivity that activity meters achieve compared with visual estrus detection ( $80 \%$ compared with $50 \%$ ) was the most important determinant of the profitability of the investment. Increasing the sensitivity of visual estrus detection by increasing labor input was more expensive than investing in activity meters. The IRR for a small herd of 65 cows (11\%) and a large herd of 195 cows $(9 \%)$ deviated $1 \%$ from the IRR for a herd of 130 cows. Given the assumptions in this study, labor had a minor effect on total costs and, therefore, on the profitability of the investment. With zero opportunity costs for labor, the IRR only decreased from 10 to $9 \%$. The investment in activity meters was profitable in most of the scenarios in the sensitivity analysis. The exceptions were an increase in sensitivity of estrus detection from 50 to $65 \%$, and the use of strict culling rules. The results of this study indicate that investment in activity meters for estrus detection is likely to be profitable for most dairy farms.

\section{ACKNOWLEDGMENTS}

We gratefully acknowledge H. Knijn (CRV, Arnhem, the Netherlands) and A. G. J. Velthuis (Animal Health Service, Deventer, the Netherlands) for the inspiring discussions. Furthermore, we thank A. Sterk (Agrifirm Innovation Center, Apeldoorn, the Netherlands) for delivering much needed input values. We also acknowledge C. Kamphuis and A. G. J. M. Oude-Lansink (both of the Business Economics Group, Wageningen University, Wageningen, the Netherlands) for their critical comments on the manuscript. This research was supported by the Dutch research program Smart Dairy Farming, which is financed by Royal Friesland Campina (Amersfoort, the Netherlands), CRV (Arnhem, the Netherlands), Royal Agrifirm (Apeldoorn, the Netherlands), Dairy Valley (Leeuwarden, the Netherlands), Investment and Development Agency for the Northern Netherlands (Groningen, the Netherlands), the Dutch Dairy Board (Zoetermeer, the Netherlands), and the ministry of Economic Affairs, Agriculture and Innovation, Pieken in de Delta (Den Haag, the Netherlands).

\section{REFERENCES}

Aramyan, L. H., A. G. J. M. Oude Lansink, and J. Verstegen. 2007. Factors underlying the investment decision in energy-saving systems in Dutch horticulture. Agric. Syst. 94:520-527.

Bewley, J. M., M. D. Boehlje, A. W. Gray, H. Hogeveen, S. J. Kenyon, S. D. Eicher, and M. M. Schutz. 2010a. Assessing the potential value for an automated dairy cattle body condition scoring system through stochastic simulation. Agric. Finance Rev. 70:126-150.

Bewley, J. M., M. D. Boehlje, A. W. Gray, H. Hogeveen, S. J. Kenyon, S. D. Eicher, and M. M. Schutz. 2010b. Stochastic simulation using @Risk for dairy business investment decisions. Agric. Finance Rev. 70:97-125.

Brickell, J. S., and D. C. Wathes. 2011. A descriptive study of the survival of Holstein-Friesian heifers through to third calving on English dairy farms. J. Dairy Sci. 94:1831-1838.

Bruijnis, M. R. N., H. Hogeveen, and E. N. Stassen. 2010. Assessing economic consequences of foot disorders in dairy cattle using a dynamic stochastic simulation model. J. Dairy Sci. 93:2419-2432. CRV. 2011. Annual report 2011. CRV, Arnhem, the Netherlands. CRV. 2012. CRV Pricelist 2012-2013. Arnhem, the Netherlands. 
de Koning, C. J. A. M. 2010. Automatic Milking-Common Practice on Dairy Farms. Pages 52-67 in Proc. 1st North Am. Conf. Precision Dairy Management, Toronto, ON, Canada.

Dechow, C. D., and R. C. Goodling. 2008. Mortality, culling by sixty days in milk, and production profiles in high- and low-survival Pennsylvania herds. J. Dairy Sci. 91:4630-4639.

Demeter, R. M., A. R. Kristensen, J. Dijkstra, A. Lansink, M. P. M. Meuwissen, and J. A. M. van Arendonk. 2011. A multi-level hierarchic Markov process with Bayesian updating for herd optimization and simulation in dairy cattle. J. Dairy Sci. 94:5938-5962.

Firk, R., E. Stamer, W. Junge, and J. Krieter. 2002. Automation of oestrus detection in dairy cows: A review. Livest. Prod. Sci. $75: 219-232$.

Galvão, K. N., P. Federico, A. De Vries, and G. M. Schuenemann. 2013. Economic comparison of reproductive programs for dairy herds using estrus detection, timed artificial insemination, or a combination. J. Dairy Sci. 96:2681-2693

Giordano, J. O., P. M. Fricke, M. C. Wiltbank, and V. E. Cabrera. 2011. An economic decision-making support system for selection of reproductive management programs on dairy farms. J. Dairy Sci. 94:6216-6232.

Giordano, J. O., A. S. Kalantari, P. M. Fricke, M. C. Wiltbank, and V. E. Cabrera. 2012. A daily herd Markov-chain model to study the reproductive and economic impact of reproductive programs combining timed artificial insemination and estrus detection. J. Dairy Sci. 95:5442-5460.

Groenendaal, H., D. T. Galligan, and H. A. Mulder. 2004. An economic spreadsheet model to determine optimal breeding and replacement decisions for dairy cattle. J. Dairy Sci. 87:2146-2157.

Hockey, C. D., J. M. Morton, S. T. Norman, and M. R. McGowan. 2010. Evaluation of a neck mounted 2-hourly activity meter system for detecting cows about to ovulate in two paddock-based Australian dairy herds. Reprod. Domest. Anim. 45:e107-e117.

Huijps, K., T. Lam, and H. Hogeveen. 2008. Costs of mastitis: Facts and perception. J. Dairy Res. 75:113-120.

Inchaisri, C., R. Jorritsma, P. Vos, G. C. van der Weijden, and H. Hogeveen. 2010. Economic consequences of reproductive performance in dairy cattle. Theriogenology 74:835-846.

Inchaisri, C., R. Jorritsma, P. Vos, G. C. van der Weijden, and H. Hogeveen. 2011. Analysis of the economically optimal voluntary waiting period for first insemination. J. Dairy Sci. 94:3811-3823.

Kamphuis, C., B. DelaRue, C. R. Burke, and J. Jago. 2012. Field evaluation of 2 collar-mounted activity meters for detecting cows in estrus on a large pasture-grazed dairy farm. J. Dairy Sci. 95:3045-3056.

LEI. 2013. LEI's Farm Accountancy Data Network. Landbouw Economische Instituut (Agricultural Economic Institute), Den Haag, the Netherlands.

Mohd Nor, N., W. Steeneveld, and H. Hogeveen. 2014. The average culling rate of Dutch dairy herds over the years 2007 to 2010 and its association with herd reproduction, performance and health. J. Dairy Res. 81:1-8.

Mollenhorst, H., L. J. Rijkaart, and H. Hogeveen. 2012. Mastitis alert preferences of farmers milking with automatic milking systems. J. Dairy Sci. 95:2523-2530.

Østergaard, S., N. C. Friggens, and M. G. G. Chagunda. 2005. Technical and economic effects of an inline progesterone indicator in a dairy herd estimated by stochastic simulation. Theriogenology 64:819-843.

Oude Lansink, A. G. J. M., J. A. A. M. Verstegen, and J. J. Van Den Hengel. 2001. Investment decision making in Dutch greenhouse horticulture. Neth. J. Agric. Sci. 49:357-368.

Palisade Corporation. 2010. @Risk. Palisade Corporation, Ithaca, NY.

Rajala-Schultz, P. J., and Y. T. Gröhn. 1999. Culling of dairy cows. Part I. Effects of diseases on culling in Finnish Ayrshire cows. Prev. Vet. Med. 41:195-208.

Remmelink, G. J., K. Blanken, J. C. van Middelkoop, W. Ouweltjes, and H. Wemmenhove. 2012. Handboek Melkveehouderij 2012 (Handbook of Dairy Farming). Livestock Research, Wageningen UR, Lelystad, the Netherlands.
Rendac Son, B. V. 2013. Pricelist. Page 2. Rendac Son BV, Son, the Netherlands.

Roelofs, J., F. López-Gatius, R. H. F. Hunter, F. J. C. M. van Eerdenburg, and C. Hanzen. 2010. When is a cow in estrus? Clinical and practical aspects. Theriogenology 74:327-344.

Russell, R. A., and J. M. Bewley. 2013. Characterization of Kentucky dairy producer decision-making behavior. J. Dairy Sci. 96:47514758 .

Rutten, C. J., A. G. J. Velthuis, W. Steeneveld, and H. Hogeveen. 2013. Invited review: Sensors to support health management on dairy farms. J. Dairy Sci. 96:1928-1952.

Seegers, H., F. Beaudeau, C. Fourichon, and N. Bareille. 1998. Reasons for culling in French Holstein cows. Prev. Vet. Med. 36:257-271.

Statistics Netherlands. 2013. Dutch statistics on: consumer prices; inflation. Statistics Netherlands, The Hague, the Netherlands.

van Asseldonk, M. A. P. M., R. B. M. Huirne, A. A. Dijkhuizen, and A. J. M. Beulens. 1999a. Dynamic programming to determine optimum investments in information technology on dairy farms. Agric. Syst. 62:17-28

van Asseldonk, M. A. P. M., A. W. Jalvingh, R. B. M. Huirne, and A. A. Dijkhuizen. 1999b. Potential economic benefits from changes in management via information technology applications on Dutch dairy farms: A simulation study. Livest. Prod. Sci. 60:33-44.

van Es, A. J. H. 1978. Feed evaluation for ruminants. I. The systems in use from May 1977-onwards in the Netherlands. Livest. Prod. Sci. 5:331-345.

Vermeij, I. 2012. Handboek Kwantitatieve Informatie Veehouderij, KWIN-V 2012-2013, Handboek 23 (Quantitative Information Livestock Farming 2012-2013, Handbook 23). Livestock Research, Wageningen UR, Lelystad, the Netherlands.

Wood, P. D. P. 1967. Algebraic model of lactation curve in cattle Nature 216:164-165.

\section{APPENDIX}

This appendix provides a description of the model and its software implementation. This description focuses on the model and provides more mathematical detail than the Materials and Methods section.

\section{Cow Simulation Model}

The cow simulation model was developed in Microsoft Excel software. For the stochastic properties of the model, the add-in software @Risk 6 for Excel (Palisade Corporation, 2010) was used. New components of the cow simulation model are described in detail in this appendix. The basic specifications of the model were described by Inchaisri et al. (2010). These new components of model included: the use of calendar weeks, the culling and replacement of cows, the transition from one lactation to the next, the reproductive cycle, the estimation of feed requirements, the simulation of falsepositive estrus alerts, and the sensitivities and specificities of estrus detection. An overview of all model inputs is given in Table 1 .

The cow simulation model, which is described schematically in Figure 1, was used to simulate fertility events of an individual cow in weekly time steps. The model simulated multiple lactations, starting with a cow in an assigned parity. In the next lactation, the 
cow shifted to the next parity unless the cow was culled during the current lactation. In parallel, fertility was simulated with the occurrence of ovulation, which could be delayed by a reproductive disease. In addition, the model simulated the detection of estrus cases. After detection of an estrus case, the cow could be inseminated. After insemination had occurred, the model simulated whether or not the cow became pregnant and the decrease in milk production due to pregnancy.

\section{Calendar Weeks}

Each iteration of the simulation model started in the first model step $(j=1)$ with the first WIM of the first lactation block $(l=1)$ of a specific cow. Parallel to each model step $(j)$, WIM $\left(\mathrm{WIM}_{j}\right)$, calendar weeks $\left[\mathrm{Wk}(\mathrm{cal})_{j}\right]$ and weeks of pregnancy $\left[\mathrm{Wk}(\mathrm{preg})_{l}\right]$ were modeled. The model simulated multiple lactation blocks $(l)$ in sequence; in the first lactation block, milk production characteristics were assigned to a cow.

In order to aggregate milk production within a specific year, the concept of calendar weeks was introduced. A calendar week represented the week of the year in which a cow calved in step $j=1$, and was randomly assigned using a uniform distribution ranging from 1 to 52, simulating a year-round calving system. From the second time step onwards, a new $\mathrm{Wk}(\mathrm{cal})_{j}$ was simulated for each time step $(j$; Equation [A1]):

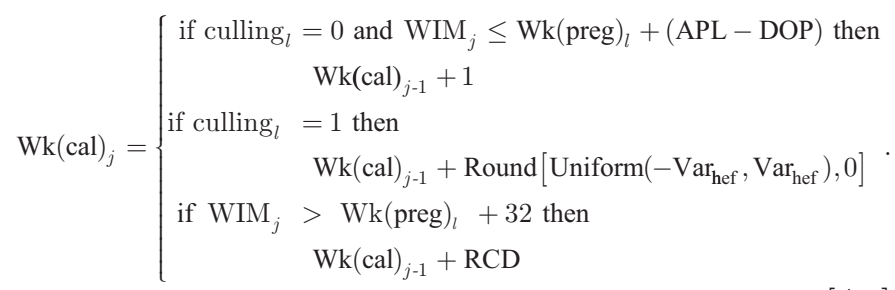

The lactation was stopped when a cow was culled or dried off. For drying off, a dry-off period (DOP) of 8 wk was assumed. When a cow was culled, a replacement heifer was assumed to be introduced into the herd during a randomly assigned period of 2 wk before to 2 wk after the last lactation week of the replaced cow $\left(\operatorname{Var}_{\text {hef }}\right)$. This 2 -wk period was simulated by rounding the outcome of a uniform distribution to the nearest integer. The moment of drying off was based on an average pregnancy length (APL) of $40 \mathrm{wk}$. At the moment of calving, the new lactation started in $\mathrm{WIM}_{j}=$ 1. Calendar weeks were continuously counted from the last $\mathrm{WIM}_{j}$ of lactation $(l)$ until the moment of calving in the new lactation $(l+1)$. When a cow conceived, she was dried off 8 wk before the expected calving date. The real calving date (RCD) was simulated using a normal distribution as in Inchaisri et al. (2010). In each time step, milk production was simulated. The parity and 305-d milk production were randomly drawn from a discrete and a normal distribution, respectively (Inchaisri et al., 2010). The 305-d milk production was adjusted for parity influence and average daily milk yield in that $\mathrm{WIM}_{j}\left(\mathrm{MY}_{l j}\right)$, using Wood's function (Wood, 1967), according to the methodology of Inchaisri et al. (2010). In parallel to milk production, ovulation, estrus detection, pregnancy, feed requirements, and false estrus alerts were simulated. The model simulated multiple lactation blocks $(l)$ in which calving, culling and replacement were modeled. In the period between conception and drying off, the average daily milk production was adjusted for the week of pregnancy. The moment of calving, in calendar weeks, was determined as the difference between the real pregnancy length (simulated pregnancy length) and the average pregnancy length.

The respective year $(k)$ was calculated by dividing the number of calendar weeks by 52 and truncating this value to the highest integer.

\section{Culling and Replacement of a Cow}

In this study, a distinction was made between general culling and culling for fertility reasons (i.e., the cow failed to become pregnant in due time). General culling was modeled as a random event, whereas culling for fertility reasons was modeled using culling rules. Whether a cow was culled $\left(\mathrm{CUL}_{l}\right)$ or not was determined for each lactation (l).

A set of culling rules was designed so that cows were culled for reproductive failure if they would exceed a certain threshold value. Cows were culled when they were either not pregnant in the week postpartum [CUL(wim)] or had the unsuccessful inseminations [CUL(ins); Table 1). After the decision to cull was made, the cow was no longer inseminated and it was culled when average daily milk production decreased below $15 \mathrm{~kg}$.

A cow was culled for general culling when the random drawing from a Bernoulli distribution was 1 . The probability of culling was derived from a frequency distribution of Dutch cows over parities (Inchaisri et al., 2010). In a specific parity, the number of cows culled was proportional to the decrease in the number of animals in the next parity compared with the number in the current parity. Therefore, the difference between the frequency of cows in parity $\mathrm{n}\left(P_{n}\right)$ and of cows in parity $\mathrm{n}+1\left(P_{n+1}\right)$ was divided by the frequency of cows in parity $\mathrm{n}\left(P_{n}\right.$; Equation $\left.[\mathrm{A} 2]\right)$ : 


$$
\mathrm{CUL}_{l}=\left\{\begin{array}{r}
\text { if parity }_{l}=1 \text { then } \\
\quad \text { Bernoulli }\left\{\left[\left(P_{1}-P_{2}\right) / P_{1}\right] \times \mathrm{ADJ}\right\} \\
\text { if parity }_{l}=2 \text { then } \\
\quad \text { Bernoulli }\left\{\left[\left(P_{2}-P_{3}\right) / P_{2}\right] \times \mathrm{ADJ}\right\} \\
\text { if parity }_{l}=3 \text { then } \\
\text { Bernoulli }\left\{\left[\left(P_{3}-P_{4}\right) / P_{4}\right] \times \mathrm{ADJ}\right\} \\
\quad 4 \text { then } \\
\text { Bernoulli }\left\{\left[\left(P_{4}-P_{5}\right) / P_{4}\right] \times \mathrm{ADJ}\right\} \\
\text { if parity }_{l} \geq 5 \text { then } \\
\text { Bernoulli }\left[\left(\left\{P_{5}-\left[1-\left(P_{1}+P_{2}+P_{3}+P_{4}+P_{5}\right)\right]\right\} / P_{5}\right) \times \mathrm{ADJ}\right] \\
\text { if parity }_{l}>5 \text { and } \leq 8 \text { then } \\
\text { Bernoulli }(0.5 \times \mathrm{ADJ}) \\
{\text { if } \text { parity }_{l}>8 \text { then }} \text { Bernoulli }(0.6 \times \mathrm{ADJ})
\end{array}\right.
$$

Full random culling would cull approximately $30 \%$ of the cows. This $30 \%$ was assumed to represent the total proportion of culled cows. Therefore, the random culling probabilities were multiplied by an ADJ to account for the split in general culling and culling for fertility reasons. It was assumed that $20 \%$ of the total number of culled cows were culled for fertility reasons (Dechow and Goodling, 2008; Brickell and Wathes, 2011; H. Knijn, Cattle Breeding Company (CRV), Arnhem, the Netherlands; personal communication).

The $\mathrm{WIM}_{j}$ in which a cow was culled $\left[\mathrm{WIM}(\text { cull })_{j}\right]$ was simulated as a random event. A $\beta$ distribution with a higher probability of culling early in lactation was used (Equation [A3]):

$$
\mathrm{WIM}(\operatorname{cull})_{j}=\operatorname{Round}[\beta \text { general }(1.3,5,1,82)] .
$$

This distribution was designed by the current authors to account for a higher culling probability early in lactation, reflecting the problems resulting from calving and diseases in early lactation (Seegers et al., 1998; Rajala-Schultz and Gröhn, 1999).

\section{Transition from One Lactation to the Next}

When a cow was culled and replaced, the parity of the cow in lactation $(l)$ was set to 1 (for the replacement heifer). A replacement heifer had a randomly assigned 305-d milk production. When the cow entered a new lactation, the cow's parity was increased by 1 . For a cow that shifted from one parity to the next, the 305-d milk production was adjusted for the influence of the increased parity (Inchaisri et al., 2010).

Between $\mathrm{WIM}_{j}=3$ and $\mathrm{WIM}_{j}=60$ of lactation $l$, the reproductive cycle of the cow was simulated parallel to milk production. The $\mathrm{WIM}_{j}$ of first ovulation and subsequent ovulations, and the occurrence of reproductive disorders that delay ovulation were simulated. Different sensitivities (i.e., estrus detection rates) were assumed for visual estrus detection and for estrus detection with activity meters (Table 1). For a specific cow that was ovulating, the detection sensitivity was adjusted for 305-d milk production and average daily milk yield in the respective WIM (Inchaisri et al., 2010). During the VWP a cow was not inseminated, even if the cow was detected to be in estrus. The average herd conception rate was $50 \%$, for a specific cow the conception rate was adjusted for $\mathrm{WIM}_{j}$, parity, 305-d milk production, and occurrence of reproductive disorders (Inchaisri et al., 2010).

\section{Estimation of Feed Requirements}

The feed requirements in model step $j$ and in lactation $l$ were calculated based on the milk production in that week. For the calculation of these requirements, the first step was to calculate the daily milk yield $\left(\mathrm{MY}_{j}\right)$ as fat- and protein-corrected milk $\left(\mathrm{FPCM}_{j}\right.$; Equation [A4]):

$\mathrm{FPCM}_{j}=(0.337+0.116 \cdot \mathrm{F} \%+0.06 \cdot \mathrm{P} \%) \cdot \mathrm{MY}_{j}$. 
Dutch average fat $(\mathrm{F} \%)$ and protein percentages $(\mathrm{P} \%)$ of 4.25 and $3.44 \%$ were assumed (CRV, 2011). Feed requirements were calculated per week in VEM as defined by van Es (1978). The feed requirements (VEM) were calculated in time step $j$ and in lactation $l$ with Equation [A5] (Remmelink et al., 2012):

$\operatorname{VEM}_{l j}=\left[5,323+400 \cdot \mathrm{FPCM}_{j}+0.73 \cdot \mathrm{FPCM}_{j}^{2}+\mathrm{ADJ}(\text { par })_{l}+\mathrm{ADJ}(\text { preg })_{l j}\right] \times 7$.

Basic feed requirements were adjusted for parity $\left[\mathrm{ADJ}(\text { par })_{l}\right]$ and pregnancy $\left[\mathrm{ADJ}(\mathrm{preg})_{l j}\right]$ using the values in Table 1.

\section{Simulation of False-Positive Estrus Alerts}

A specificity of $100 \%$ was assumed for visual estrus detection by the farmer and a specificity of $95 \%$ was assumed for the activity meter. A daily probability of a false estrus alert existed during the period after the VWP and before the first week of pregnancy, and in a WIM in which the cow was not in estrus. The occurrence of a false alert in $\mathrm{WIM}_{j}\left(\mathrm{FAL}_{j}\right)$ was simulated by a random draw from a Binomial distribution with 7 tri- als $(\mathrm{n}=7)$, which accounted for the daily test protocol of the sensor in that WIM (Equation [A6]):

$\mathrm{FAL}_{j}=\left\{\begin{array}{l}\text { if ovulation }=0 \text { and if pregnancy }=0 \text { and if } \mathrm{WIM}_{j}>\mathrm{VWP} \text { then } \\ \operatorname{Binomial}(1-\text { sensor specificity }, \mathrm{n}=7)\end{array}\right.$.

\section{Sensitivities and Specificities of Estrus Detection}

In this simulation study, activity meters that are attached to a cow with a neck collar were the analyzed sensor system. An activity meter measures the acceleration of the cow's movement in 3 dimensions. From this data, behavioral parameters are calculated that are used to detect estrus. The performance of such sensors has been reported to have sensitivities in the range of 79 to $94 \%$, with specificities in the range of 90 to $98 \%$ (Hockey et al., 2010). Another study indicated sensitivities in the range of 62 to $77 \%$, with a specificity of $99 \%$ (Kamphuis et al., 2012). On the basis of these reported performances, the current study used $80 \%$ sensitivity and $95 \%$ specificity for activity meters. For visual estrus detection, $50 \%$ sensitivity and $100 \%$ specificity was assumed. 